\title{
Relative power of clinical, exercise test, and angiographic variables in predicting clinical outcome after myocardial infarction: the Newham and Tower Hamlets study
}

\author{
MARK A DE BELDER, CHARLES W PUMPHREY, J DOUGLAS SKEHAN, \\ HELEN RIMINGTON, BAHA AL WAKEEL, STEPHEN J W EVANS, \\ MARTIN T ROTHMAN, PETER G MILLS \\ From the Cardiac Department and the Department of Clinical Epidemiology, The London Hospital, London
}

SUMMARY The interrelations of clinical, exercise test, and angiographic variables and their relative values in predicting specific clinical outcomes after myocardial infarction have not been fully established. Of 302 consecutive stable survivors of infarction, 262 performed a predischarge submaximal exercise test. In the first year after infarction patients with a "positive" exercise test were 13 times more likely to die, 2.8 times more likely to have an ischaemic event, and 2.3 times more likely to develop left ventricular failure than patients with negative tests. Patients with positive exercise tests underwent cardiac catheterisation. Features of the history, 12 lead electrocardiogram, in-hospital clinical course, exercise test, and left ventricular and coronary angiograms that predicted these clinical end points were identified by univariate analysis. Then multivariable analysis was used to assess the relative powers of all variables in predicting end points. Certain features of the exercise test remained independent predictors of future ischaemic events and the development of overt left ventricular failure, but clinical and angiographic variables were more powerful predictors of mortality. Because the exercise test is also used to select patients for angiography, however, the results of this study strongly support the use of early submaximal exercise testing after infarction.

An early submaximal exercise test can detect high and low risk groups after acute myocardial infarction. ${ }^{1-3}$ Although interactions between exercise and angiographic variables have been investigated in part, ${ }^{4-6}$ the interactions between clinical and exercise variables are still unclear. ${ }^{7}$ Prognosis is related to left ventricular dysfunction, ${ }^{89}$ arrhythmias, ${ }^{111}$ and the presence of certain patterns of coronary artery disease. ${ }^{12}{ }^{13}$ The relative powers of variables in predicting particular clinical outcomes must be assessed by multivariable (rather than univariate) analysis.

The results of any study of outcome of clinically stable survivors after myocardial infarction must take

Requests for reprints to Dr Mark A de Belder, Department of Cardiological Sciences, St George's Hospital Medical School, Tooting, London SW17 ORE.

Accepted for publication 23 May 1988 account of potential differences between the total population and the proportion that has been studied in depth; these differences are the most important factor in determining whether recommendations generated from the results of a study hold for all such survivors or whether they apply only to a small subset. We therefore designed this study to investigate the relative powers of clinical, exercise test, and angiographic features in predicting death, further ischaemic events, and left ventricular failure in a defined population from two adjacent health districts.

\section{Patients and methods}

Two centres contributed to this study-The London Hospital, Whitechapel, London E1 and Newham General Hospital, London E13.

Consecutive patients aged $\leqslant 65$ who were clinically stable seven days after admission to hospital 
with a diagnosis of myocardial infarction were included in this study. Patients with haemodynamically important valve disease were excluded. For a diagnosis of myocardial infarction two out of the following three criteria had to be met: (a) typical cardiac pain lasting at least half an hour; $(b)$ a typical rise in the enzymes aspartate aminotransferase and lactate dehydrogenase; $(c)$ changes on consecutive resting electrocardiograms consistent with $Q$ wave ( $>0.04 \mathrm{~s}$ duration and $>25 \%$ of amplitude of subsequent $R$ wave) or non- $Q$ wave infarction; for a diagnosis of non- $Q$ wave infarction, cardiac enzymes had to be raised to at least double the local laboratory upper limit of normal.

Changes in leads I, aVL, and V1-V4 were defined as anterior; changes in leads II, III, and aVF were defined as inferior; changes in V5 and V6 were defined as inferior if accompanied by changes in two out of the three leads II, III, and aVF, otherwise they were classified as anterior. Previous infarction was defined as a history of infarction supported by evidence from hospital notes of two of the above factors, or the presence of $Q$ waves on the initial electrocardiogram in a territory showing no evolving changes.

\section{STUDY GROUP}

Three hundred and two consecutive, clinically stable, survivors of myocardial infarction (group 1) were identified. Table 1 gives the demographic details.

\section{EXCLUSION GROUP}

Fifteen patients were excluded because either they were unable to perform an exercise test or it would have been impossible to interpret the electrocardiograms (fig 1). These were (a) 10 with physical disabilities (three with severe chronic obstructive airways disease; five with severe locomotor problems; one with a disabling cerebrovascular accident after infarction; one with multiple systemic emboli after infarction), (b) four with left bundle branch block; and $(c)$ one who developed unstable angina after the seventh day but before being able to perform an exercise test.
GROUP 1: STABLE SURVIVORS OF ACUTE MI (302)

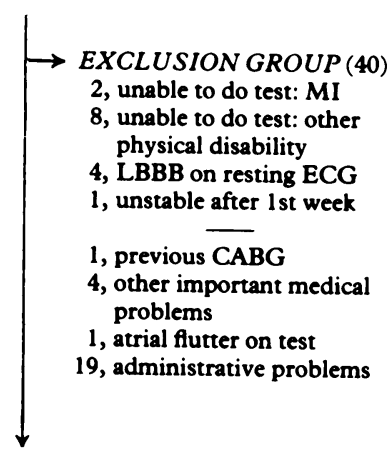

GROUP 2: EXERCISE TEST GROUP (262)

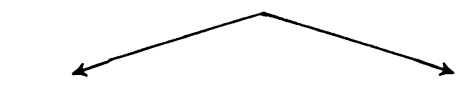

POSITIVE TEST (139)

NEGATIVE TEST (123)

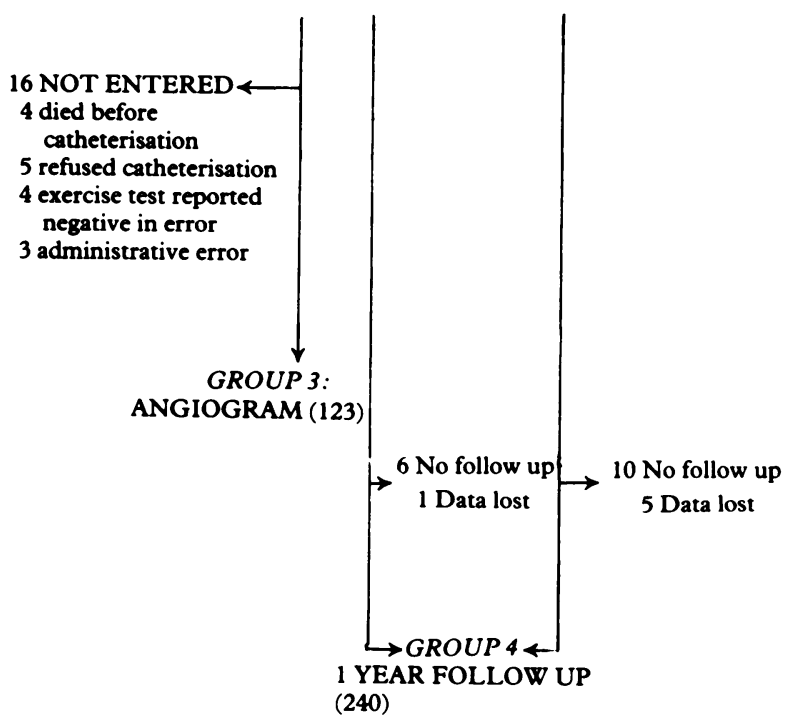

Fig 1 Study outline. $C A B G$, coronary artery bypass grafting; MI, myocardial infarction; ECG, electrocardiogram; $L B B B$, left bundle branch block.

Twenty five other patients were not entered into the exercise test group: (a) one with previous coronary artery bypass grafting, $(b)$ four with other significant medical conditions (two with severe alcohol-

Table 1 Demographic data on study groups

\begin{tabular}{|c|c|c|c|c|c|c|c|c|c|}
\hline \multirow{2}{*}{\multicolumn{2}{|c|}{ Group }} & \multirow[b]{2}{*}{ No } & \multirow[b]{2}{*}{$\begin{array}{l}\text { Mean age } \\
(S D)\end{array}$} & \multicolumn{2}{|l|}{ Men } & \multicolumn{2}{|l|}{ Women } & \multicolumn{2}{|l|}{ Asians } \\
\hline & & & & No $(\%)$ & $\begin{array}{l}\text { Mean age } \\
(S D)\end{array}$ & No $(\%)$ & $\begin{array}{l}\text { Mean age } \\
(S D)\end{array}$ & No $(\%)$ & $\underset{(S D)}{\text { Mean }}$ ase $\frac{0}{\mathbb{D}}$ \\
\hline 2 & Stable survivors of MI & 302 & $54(7 \cdot 3)$ & $254(84)$ & $54(7 \cdot 4)$ & $48(16)$ & $57(5 \cdot 5)$ & $58(20)$ & $51(6 \cdot 7) \stackrel{\circledR}{\varrho}$ \\
\hline 3 & Patients with angiograms & 123 & $54(7 \cdot 1)$ & $104(84)$ & $53(7 \cdot 2)$ & $20(16)$ & $56(5 \cdot 8)$ & $16(13)$ & $50(8.9) \stackrel{2}{\circ}$ \\
\hline 4 & Exercise test + follow up & 240 & $54(7 \cdot 2)$ & $206(86)$ & $53(7 \cdot 4)$ & $34(14)$ & $56(5 \cdot 6)$ & $42(18)$ & $50(7 \cdot 0)$ ్ㅡㅇ \\
\hline
\end{tabular}


ism; two with malignant disease); (c) one patient attempted an exercise test but it was stopped early because rapid atrial flutter developed; the inclusion protocol had not allowed for such a development; $(d)$ 19 did not enter because of administrative problems.

\section{EXERCISE TEST GROUP (GROUP 2)}

This study therefore analyses the data from 262 patients, all of whom undertook an early submaximal exercise test. No $\beta$ blockers had been prescribed for 36 hours and digoxin had been stopped at least seven days before the exercise test.

\section{Exercise test protocol}

Patients were exercised for the second and third stages of the modified Bruce protocol; the treadmill was set at a speed of $2.75 \mathrm{kph}$, and the gradients set for the two stages were $2.9^{\circ}$ and $5.8^{\circ}$ respectively. Three minutes' exercise was performed in each stage. Patients were tested a median of 11 days after infarction (interquartile range 9-12). Cuff systolic blood pressure measurements and a 12 lead electrocardiogram were recorded before the test with the patient standing upright on the treadmill; at the end of each 3 minute stage; and at the end of 2, 5, and 10 minutes of the recovery phase.

The test was stopped early if any of the following features developed: $(a)$ severe angina pectoris; $(b)$ severe dyspnoea, fatigue, or ataxia; (c) ST depression of $\geqslant 5 \mathrm{~mm}, 80 \mathrm{~ms}$ after the J point; (d) 10 ventricular extrasystoles per minute or ventricular triplets.

A positive exercise test was defined as the development of $(a)$ angina pectoris; $(b)$ horizontal or downsloping ST depression $\geqslant 1 \mathrm{~mm}, 80 \mathrm{~ms}$ after the J point; (c) an inappropriate blood pressure response defined as failure of the systolic blood pressure to rise $10 \mathrm{~mm} \mathrm{Hg}$ or more, or, having risen, to fall again by $10 \mathrm{~mm} \mathrm{Hg}$ or more (the latter finding had to be confirmed immediately the patient stopped exercising); ( $d$ ) inability to complete the exercise test because of severe dyspnoea, fatigue, or ataxia; (e) increase in the frequency of ventricular extrasystoles of $>6$ greater than the count on the pre-exercise electrocardiogram or development of ventricular triplets.

\section{GROUP UNDERGOING CARDIAC}

CATHETERISATION (GROUP 3 )

Cardiac catheterisation was performed at a median of 21 (interquartile range, 16-31) days after infarction in patients with a positive exercise test. One hundred and thirty nine patients $(53 \%$ of group 2$)$ were defined as having a positive exercise test but 16 of these patients did not undergo catheterisation for the following reasons: (a) four died before cardiac catheterisation; (b) five refused cardiac catheterisation; (c) four had exercise tests erroneously reported as "negative" (in each case an inappropriate blood pressure response had been overlooked) and were not therefore put forward for catheterisation; $(d)$ three because of administrative error.

Study group 3 therefore consisted of 123 patients with a positive exercise test all of whom underwent cardiac catheterisation. Table 1 summarises their demographic data.

\section{Follow up}

The "positive" group were all prescribed a $\beta$ blocker (sotalol), unless it was contraindicated, one to two days before discharge at a dose sufficient to reduce the resting heart rate to $\leqslant 60$. Patients with angina were treated with oral nitrates and calcium channel blockers and coronary artery bypass grafting was offered if they had angina resistant to medical treatment or left main stem stenosis or triple vessel disease with symptoms or exercise induced ST segment depression. Diuretics and vasodilators for heart failure were added as appropriate. Antiarrhythmic agents were given at the discretion of the physician under whose care the patient had originally been admitted. Treatment for the "negative" group was not standardised. Relevant follow up data were collected for one year after infarction.

Sixteen of the 262 patients in group 2 were lost to follow up (fig 1); six of these were from the "positive" exercise group and 10 were from the "negative" test

Site of infarction

\begin{tabular}{|c|c|c|c|c|c|c|}
\hline \multicolumn{2}{|c|}{ Anterior $(\%)$} & \multicolumn{2}{|c|}{ Inferior $(\%)$} & \multirow[b]{2}{*}{ Both $(\%)$} & \multirow[b]{2}{*}{ Unknown $(\%)$} & \multirow[b]{2}{*}{ Prev $M I 1^{\circ} \%$} \\
\hline$Q(\%)$ & non- $Q(\%)$ & $Q(\%)$ & non- $Q(\%)$ & & & \\
\hline \multirow{3}{*}{\multicolumn{2}{|c|}{$\begin{array}{cc} & 143(47) \\
104(73) & 39(27) \\
& 54(44) \\
40(74) & 14(26) \\
& 116(48) \\
87(75) & 29(25)\end{array}$}} & \multirow{3}{*}{\multicolumn{2}{|c|}{$\begin{array}{cc} & 141(47) \\
88(62) & 53(38) \\
& 66(53) \\
33(50) & 33(50) \\
& 115(48) \\
64(56) & 51(44)\end{array}$}} & $9(3)$ & $9(3)$ & $28(9 \cdot 3)$ \\
\hline & & & & $4(3 \cdot 2)$ & $0(0)$ & $15(12)$ \\
\hline & & & & $9(3 \cdot 8)$ & $0(0)$ & $21(8 \cdot 8)$ \\
\hline
\end{tabular}


group. It was not possible to interpret the exercise tests of a further six patients because these tests were missing at the time of analysis, although they were recorded as being "negative" in five and "positive" in one. Follow up on these six was complete.

There were thus 240 patients with interpretable exercise tests with complete follow up (study group 4) (table 1). The data on these 240 patients were analysed and related to clinical outcome in the first year after infarction.

The study was approved by the ethics committees of both hospitals. All patients gave informed consent.

\section{STATISTICAL ANALYSIS}

Variables were entered into a data base on a Sperry PC/IT computer and analysed with the SPSS/PC+ program. We used $\chi^{2}$ analysis to compare groups defined by unordered categorical variables and Kendall's tau-C test for groups defined by ordered categorical variables. Means were compared by an analysis of variance method. Likelihood ratios were calculated where appropriate. ${ }^{14}$ Certain variables, selected on the basis of the results of univariate analysis were used in log-linear analysis (SPCC/ PC + hiloglinear procedure). In each model, three variables were selected; those not contributing to prognosis were replaced until all variables had been included. A total of 60 variables were collected from which others were calculated; these described features of the history (demographic data, risk factors, and previous history), early 12 lead electrocardiogram, early (predischarge) clinical events, exercise test, angiograms, clinical follow up, and therapeutic manoeuvres. Collection of data was almost complete, but because this study was designed to study the power of an abnormal exercise test, we recorded the early clinical events only for patients with positive exercise tests. These data were also available for 17 of the $\mathbf{4 0}$ patients in the exclusion group, but they were not collected for patients with negative exercise tests. These clinical events included the following: ventricular arrhythmias (ventricular fibrillation, ventricular tachycardia, or ventricular extrasystoles that required treatment) in the early $(\leqslant 72 \mathrm{~h})$ and late $(>72 \mathrm{~h})$ period; left ventricular failure defined as a requirement for more than one dose of $\mathbf{4 0} \mathrm{mg}$ frusemide; hypotension defined as a systolic blood pressure $<90 \mathrm{~mm} \mathrm{Hg}$; recurrent ischaemic pain $>48 \mathrm{~h}$ after infarction. Cardiac catheterisation provided several continuous variables. Two independent observers analysed the coronary arteriograms for the number of major vessels (left anterior descending, left circumflex, right coronary and the major intermediate artery) with a stenosis $>50 \%$. Figure 2 shows how the overall coronary artery score was derived. The left

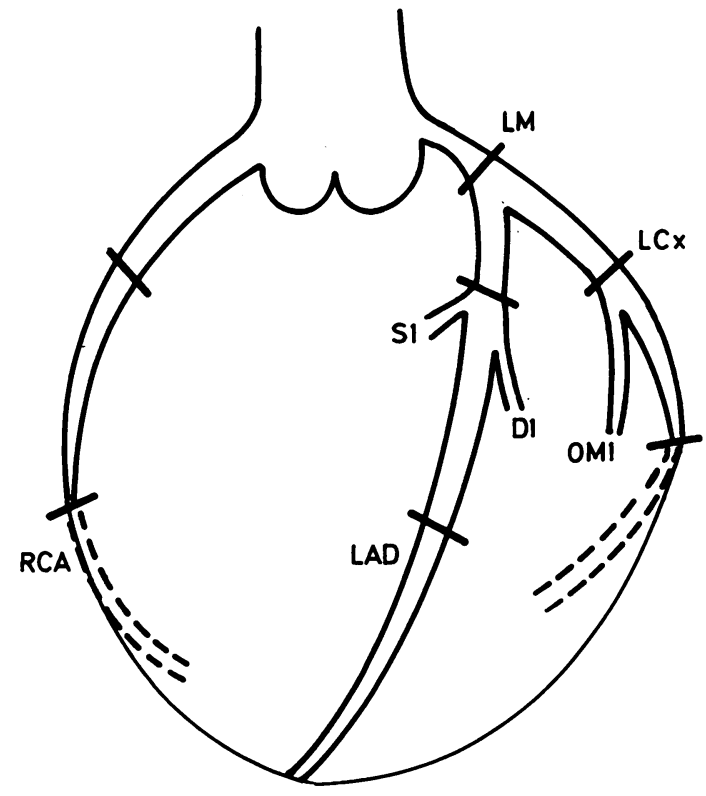

Fig 2 Coronary artery scoring system. Diagram of the left anterior oblique view of coronary arteries as seen at angiography. LM, left main stem; $L A D$, left anterior descending; LCx, left circumflex; $R C A$, right coronary; $D 1$, first diagonal branch; $S 1$, first septal branch;

OM1, first obtuse marginal branch.

The analysis was based on four major vessels (left anterior descending, left circumflex, right coronary, and the major intermediate (larger of major diagonal and obtuse marginal)) and the left main stem. Each major vessel (except left main stem) has three segments-proximal, middle, and distal. Each segment was given a score for:

$\begin{array}{lll}\text { Degree of stenosis } & \text { Score } & \begin{array}{l}\text { Score for proximal } \\ \text { segment/left main stem }\end{array} \\ 0 \% & 0 & 0 \\ 0-25 \% & 1 & 2 \\ 25-50 \% & 2 & 4 \\ 50-75 \% & 3 & 6 \\ 75-99 \% \text { (sub-total } & & 8 \\ \text { occlusion) } & 4 & 8 \\ 100 \% \text { (total occlusion) } & 8 & 10\end{array}$

ventricular angiogram was assessed according to a wall motion score based on that used in Coronary Artery Surgery Study. ${ }^{15}$ Collateral vessels to the infarct territory were scored as follows: 0 , no collaterals; 1 , faint blush of vessels only; 2 , small collateral vessels easily seen, but insufficient to fill the epicardial portion of the infarct related artery; 3, collaterals easily seen, but only faintly filling the epicardial portion of the infarct related artery; 4, collaterals easily seen and fully filling the epicardial part of the infarct related artery.

Only positive findings and relevant associations are reported in detail. 
Results

ANALYSIS OF DEMOGRAPHIC DATA

Differences between patient groups

Table 1 shows that there were no important differences in the distribution of age and sex between the groups. The data were analysed to investigate the characteristics of patients who did not undergo an exercise test or cardiac catheterisation or who were lost to follow up.

Those who did not perform an exercise test (group $1 v$ group 2)-The 40 patients who did not perform an exercise test (the exclusion group (fig 1)) had a higher mortality (19v6.1\%,p = 0.002), a higher mean age (59 $v 54, \mathrm{p}=0.0001$ ), and were more likely to have had a previous infarction ( $22 v 8 \%, p=0.01)$ and to be female ( $30 v 14 \%, \mathrm{p}=0.009$ ). There was no difference in the distribution of risk factors, site or type of infarction, or race.

Those lost to follow up (group 1 v group 4)-More Asian patients (19 $v 6.9 \%$ of non-Asians, $p=0.005$ ) and more diabetic patients (19 $v 7.2 \%$ of nondiabetics, $p=0.03$ ) were lost to follow up but there were no differences in age, sex, site or type of infarction, history of previous infarction, or other risk factors between those who were lost to follow up and those who were not.

Those who did not undergo cardiac catheterisationSixteen patients had a positive exercise test but did not undergo cardiac catheterisation ("Not entered", fig 1). The mortality of this group was significantly greater than that of the patients who had catheterisation (25 $v 8.4 \%, p=0.02)$. There were no other significant differences between these two groups.

\section{INTERRELATIONS OF THE VARIABLES}

To assess the predictive value of different variables derived from clinical data, exercise testing, and angiography, we analysed the pre-existing relations between the individual variables within these categories. Risk factor data were available for 260 patients, and early 12 lead electrocardiograms were available for 266 patients. Because the early clinical events were not recorded for the patients with negative exercise tests, there were only 155 patients with these variables recorded (132 of the 139 with positive exercise tests and all except 17 of the 40 patients in the exclusion group); exercise test variables for group 4 were virtually complete for all 240 patients; angiographic variables were available for all 123 patients undergoing the test, but in one patient left ventricular angiography was not performed because the procedure was stopped after arteriography.

\section{Risk factor analysis (Group 1)}

Risk factor data were available in all but seven of the
302 patients in group 1; of the remaining 295, 238 $(81 \%)$ were smokers, $67(23 \%)$ had a positive family history, $48(16 \%)$ gave a history of previously diagnosed hypertension, $32(11 \%)$ had previously had diabetes diagnosed, five $(1.7 \%)$ had gout, and only one $(0.3 \%)$ gave a history of hyperlipidaemia. Thirty five $(12 \%)$ had no risk factors.

\section{Interrelations of data acquired from the history (from group 1) (table 1)}

The mean age for men was significantly lower than that for women $(p=0.005)$, and that of the Asian men was significantly lower than that of the nonAsian men $(p=0.0003)$. The mean age of those who gave a history of previous infarction was not significantly higher than that of those with first infarcts. More women than men had a positive family history (37 $v 20 \%, p=0.01$ ), and more had had hypertension diagnosed ( $26 v 14 \%, \mathrm{p}=0.05)$. More diabetic patients than non-diabetic patients were known to have hypertension ( $31 v 14 \%, \mathrm{p}=0.02)$. Although proportionately more of the diabetic patients were non-smokers than the non-diabetic patients (31 v $18 \%$ ), this difference was not statistically significant. A higher percentage of diabetic patients had electrocardiographic evidence of infarction in both anterior and inferior territories but the difference between the diabetic and non-diabetic patients was not significant.

\section{Interrelations of early clinical events}

Among the patients for whom these data were available (a relatively high risk group), only two significant associations were found: (a) three $(16 \%)$ of the 19 patients in whom angina developed $>48 \mathrm{~h}$ after onset of the chest pain that prompted admission to hospital had late ( $>72$ hours after infarction) ventricular arrhythmias compared with three $(2 \%)$ of 151 patients without such angina $(p=0.02) ;(b)$ three $(9.7 \%)$ of 31 patients in whom early left ventricular failure developed also had early ( $\leqslant 72$ hours) ventricular arrhythmias compared with one $(0.7 \%)$ of 139 patients without failure $(p=0.02)$.

\section{Interrelations of exercise test variables (table 2)}

There were very strong interrelations between the development of ST depression, angina, and an abnormal blood pressure response; ST depression in the non-infarct zone of the electrocardiogram was also associated with $S T$ elevation in leads showing $Q$ wave infarction. There was also a very strong association between the development of angina and both an abnormal blood pressure response and an inability to complete the exercise protocol. There were weaker but significant associations between an abnormal blood pressure response and an inability to complete 
Table 2 Interrelations of exercise test variables

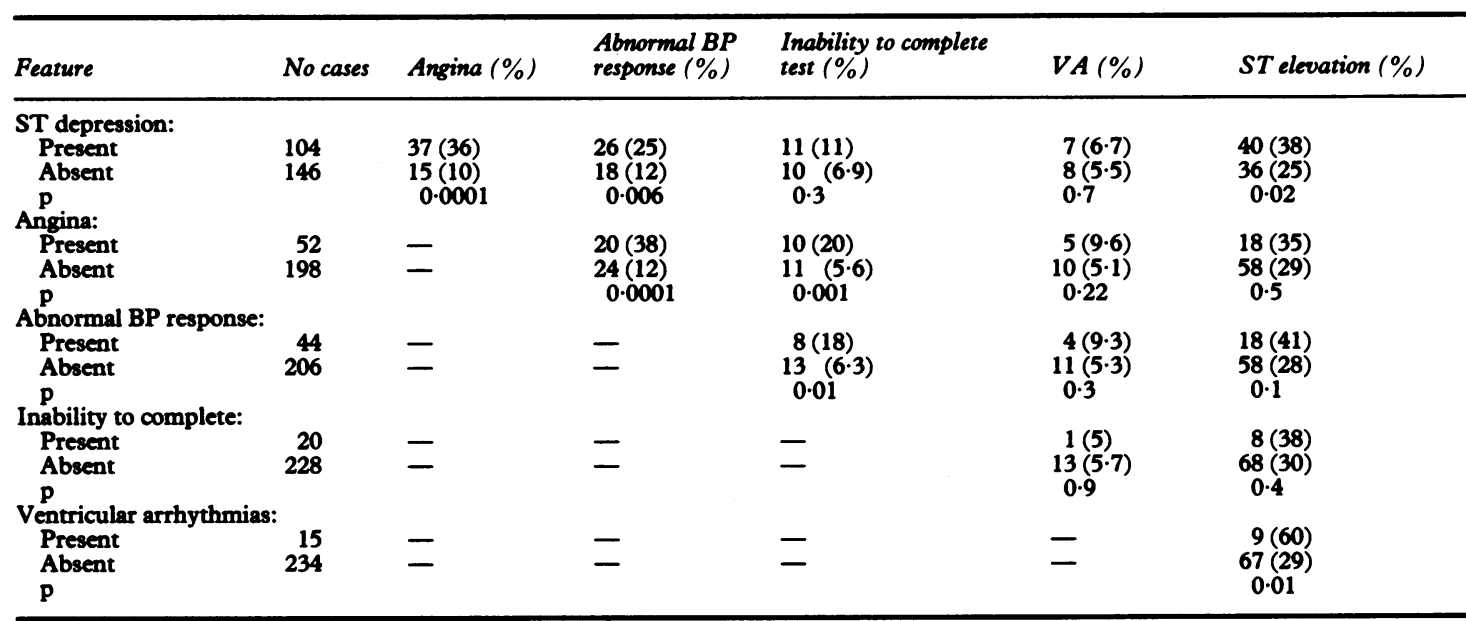

Only cases for which all the data were available were analysed.

$p$ values are significance levels for $\chi^{2}$ tests before Yates' correction.

BP, blood pressure; VA, ventricular arrhythmia.

the test, and also between the development of a ventricular rhythm disturbance and the development of ST elevation.

Interrelations of angiographic variables (table 3)

There was no interrelation between the left ventricular and coronary artery scores nor between the left ventricular and collateral scores. There was, however, a highly significant association between the coronary artery and collateral scores. The group of patients with high coronary artery scores $(\geqslant 19$, see below) were nearly three times more likely to have obvious collaterals (scores 3 and 4) than the group with low coronary artery scores.

\section{Interrelations of end points}

The clinical outcomes, that is cardiac death, an "ischaemic" end point (development of angina, further infarction, or requirement for operation), and the development of overt left ventricular failure were analysed by the hiloglinear procedure. There were no associations between these end points other than a non-significant relation between the development of overt left ventricular failure and mortality. Fourteen of the patients who underwent an exercise test died in the first year; 10 died suddenly (one each at 10, 11, and 14 days after infarction, one at two months, three at three months, and one each at five, seven, and nine months after infarction). Two of them had ventricular fibrillation; two died within an hour of complaining of chest pain; two patients died after confirmed recurrent myocardial infarction; one died in congestive heart failure at two months; one died of unknown cause at one month. The "ischaemic" end points were interrelated. Thirty $(27 \%)$ of the 113 patients who developed angina in the first year after discharge underwent coronary surgery compared with two $(1.3 \%)$ of 157 patients who did not complain of angina ( $p<0.0001)$; the development of further infarction, however, was unrelated to the development of angina or the need for operation.

SAFETY OF EARLY SUBMAXIMAL EXERCISE TEST There was no mortality and no.major complication

Table 3 Relation of collateral score to left ventricular $(L V)$ and coronary artery $(C A)$ scores

\begin{tabular}{|c|c|c|c|c|c|c|c|c|}
\hline $\begin{array}{l}\text { Collateral } \\
\text { score }\end{array}$ & $\begin{array}{l}\text { CA score } \\
\geqslant 19\end{array}$ & $\begin{array}{l}\text { CA score } \\
<19\end{array}$ & $\begin{array}{l}\text { Likelihood } \\
\text { ratio }\end{array}$ & $\begin{array}{l}\text { Relative } \\
\text { odds }\end{array}$ & $\begin{array}{l}L V \text { score } \\
\geqslant 21\end{array}$ & $\begin{array}{l}L V \text { score } \\
<21\end{array}$ & $\begin{array}{l}\text { Likelihood } \\
\text { ratio }\end{array}$ & $\begin{array}{l}\text { Relative } \\
\text { odds }\end{array}$ \\
\hline $\begin{array}{l}4 \\
3\end{array}$ & $\begin{array}{l}39 \\
11\end{array}$ & $\begin{array}{l}15 \\
13\end{array}$ & $\left.\begin{array}{l}2 \cdot 2 \\
1.5\end{array}\right\}$ & 2.9 & $\begin{array}{l}25 \\
12\end{array}$ & $\begin{array}{l}28 \\
12\end{array}$ & $\left.\begin{array}{l}0.84 \\
0.87\end{array}\right\}$ & 1.0 \\
\hline $\begin{array}{l}2 \\
1 \\
0\end{array}$ & $\begin{array}{r}4 \\
3 \\
10\end{array}$ & $\begin{array}{r}6 \\
6 \\
16\end{array}$ & $\left.\begin{array}{l}1 \cdot 3 \\
1.2 \\
1.0\end{array}\right\}$ & 1.0 & $\begin{array}{r}3 \\
9 \\
14\end{array}$ & $\begin{array}{r}7 \\
0 \\
12\end{array}$ & $\left.\begin{array}{l}0.80 \\
0.98 \\
1.0\end{array}\right\}$ & 1.5 \\
\hline
\end{tabular}

^For cut off point, not for individual collateral score. 
Table 4 Discriminatory power of the "positive" submaximal exercise test

\begin{tabular}{|c|c|c|c|c|c|c|c|c|c|}
\hline $\begin{array}{l}\text { Exercise } \\
\text { test result }\end{array}$ & No cases & Deaths & $\begin{array}{l}\text { Relative } \\
\text { odds }\end{array}$ & $\begin{array}{l}\text { "Ischaemic } \\
\text { event" }\end{array}$ & $\begin{array}{l}\text { Relative } \\
\text { odds }\end{array}$ & $L V F$ & $\begin{array}{l}\text { Relative } \\
\text { odds }\end{array}$ & $\begin{array}{l}\text { Well (none } \\
\text { of these) }\end{array}$ & $\begin{array}{l}\text { Relative } \\
\text { odds }\end{array}$ \\
\hline $\begin{array}{l}\text { Positive } \\
\text { Negative }\end{array}$ & $\begin{array}{l}133 \\
113\end{array}$ & $\stackrel{14}{1}$ & $\begin{array}{l}\text { With oun } \\
13 \\
1 \\
\text { in the infa }\end{array}$ & $\begin{array}{l}\text { edetermined cr } \\
76 \\
34 \\
\text { territory adde }\end{array}$ & $\begin{array}{l}\text { iteria for } p \\
2 \cdot 8 \\
1 \\
\text { d as an add }\end{array}$ & $\begin{array}{l}\text { ivity } \\
8 \\
3 \\
\text { mal feat }\end{array}$ & $\begin{array}{l}2 \cdot 3 \\
1 \\
\text { positivity }\end{array}$ & $\begin{array}{l}35 \\
75\end{array}$ & $\begin{array}{l}1 \\
5.5\end{array}$ \\
\hline $\begin{array}{l}\text { Positive } \\
\text { Negative }\end{array}$ & $\begin{array}{r}153 \\
93\end{array}$ & $\begin{array}{r}15 \\
0\end{array}$ & $\stackrel{\infty}{-}$ & $\begin{array}{l}80 \\
30\end{array}$ & $\begin{array}{l}2 \cdot 3 \\
1\end{array}$ & $\begin{array}{l}9 \\
2\end{array}$ & & $\begin{array}{l}49 \\
61\end{array}$ & $\begin{array}{l}1 \\
4 \cdot 0\end{array}$ \\
\hline
\end{tabular}

from the early submaximal exercise test. In four patients well tolerated ventricular tachycardia developed; one required a precordial thump to restore sinus rhythm; the others had short lived, self terminating events.

\section{DISCRIMINATORY POWER OF THE "POSITIVE" EXERCISE TEST (TABLE 4)}

A patient with a positive test was 13 times more likely to die in the year after infarction than a patient with a negative exercise test. A patient with a positive test was nearly three times more likely to have a further infarct, develop angina, or require coronary artery bypass grafting than a patient with a negative test. In addition, those patients with a positive exercise test were more than twice as likely to develop overt left ventricular failure in the first year after infarction.

The data were re-analysed to investigate whether the addition of ST elevation as a positive feature improved the discriminatory power of the exercise test. The prediction of death and overt left ventricular failure was improved, but the test became a weaker predictor of further ischaemic events. The predictive accuracy of a negative test for a good outcome was weakened by the inclusion of ST elevation.

\section{PROGNOSTIC POWER OF VARIABLES}

Predictors of mortality (table 5)

Univariate analysis-Table 5 shows the features of the history, early 12 lead electrocardiogram, early clinical events, exercise test, and angiogram that were predictive of mortality and the relative odds for mortality associated with these variables. The mean left ventricular score of those who died was significantly higher than that of survivors. Patients with a left ventricular score of $\geqslant 30$, for example, were six times more likely to die than the rest of the group (see fig 3a). Patients with a left ventricular score of $\geqslant 21$ were twice as likely to die than those with a lower score. The coronary artery score on the other hand was not a predictor of death in the first year after infarction (see fig 4b), nor was the collateral score related to mortality.

Multivariable analysis-(a) Features of history and early 12 lead electrocardiogram. A history of previous infarction was the only powerful predictor of mortality in the first year $(p=0.003)$ and a history of diabetes added some additional prognostic information ( $p=0.05)$. The other variables did not remain independent predictors. (b) Features of exercise test alone and together with clinical variables. For the whole group the development of ventricular arrhythmias was the most powerful predictor of mortality from the exercise test ( $p=$ 0.007 ), although a blood pressure of $\leqslant 100 \mathrm{~mm} \mathrm{Hg}$ at the beginning of the exercise test $(p=0.03)$ and inability to complete the test $(p=0.04)$ were also independent markers for this end point. For the subgroup of patients who completed six minutes of exercise, a blood pressure of $\leqslant 130 \mathrm{~mm} \mathrm{Hg}$ at the end of exercise was the only predictor of mortality ( $p=$ 0.02 ). Analysis of these variables together with the features from the history, electrocardiogram, and early clinical events showed that for the whole group the development of ventricular arrhythmias on the exercise test ( $p=0.02$ ) and the development of ventricular arrhythmias $>72$ hours after infarction ( $p=0.03$ ) were independent markers for mortality. (c) All features, including angiographic variables. A left ventricular score $\geqslant 21$ was added to the previous variables from the history and exercise test. Both a high left ventricular score $(p=0.0003)$ and ventricular arrhythmias occurring $>72$ hours after infarction ( $p=0.04$ ) were independent predictors of mortality in this group of patients.

\section{PREDICTORS OF "ISCHAEMIC" END POINTS} The development of angina pectoris, further infarction, or a requirement for coronary artery bypass grafting in the first year after infarction were all regarded as ischaemic end points.

\section{Univariate analysis}

Table 5 shows the variables identified as predictors of an ischaemic end point and their associated relative odds. The coronary artery score was predictive of the development of an ischaemic end point; those with a score $>30$ were over three and a half times more 
Table 5 Predictors of clinical end points (univariate analysis)

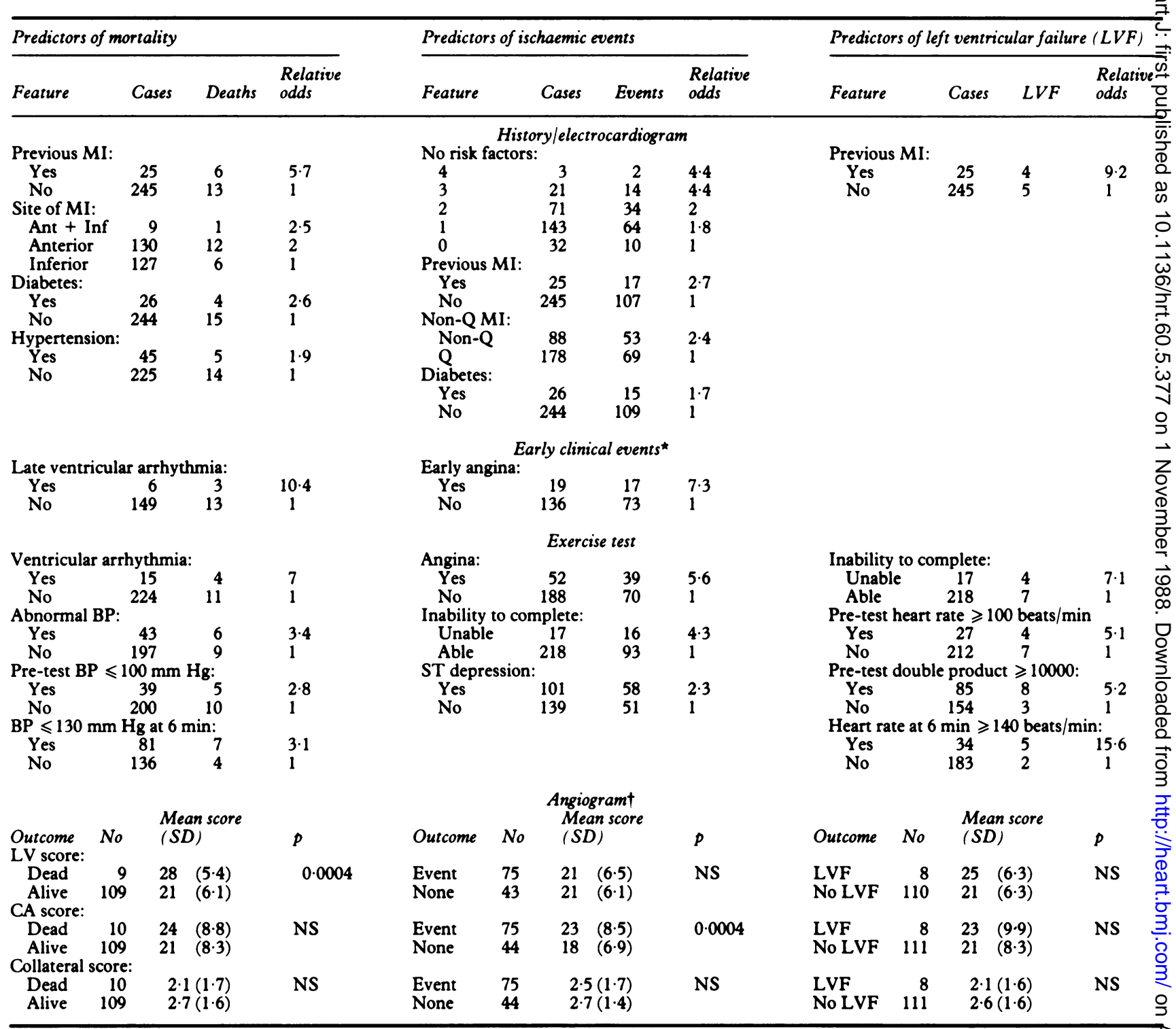

^Not recorded for patients with negative exercise tests; late ventricular arrhythmias occurred $>72 \mathrm{~h}$ after infarction but before discharge; early angin occurred $>48 \mathrm{~h}$ after infarction but before discharge.

tOne patient had coronary arteriography but not left ventricular angiography.

LVF, left ventricular failure; BP, blood pressure; LV, left ventricular; CA, coronary artery; $M I$, myocardial infarction.

likely to have such an end point than those with a lower score (fig 4a); the chances of such an end point were doubled with a coronary score of $\geqslant 19$. The left ventricular and collateral scores did not contribute to the prediction of these end points.

\section{Multivariable analysis-(a) Features of history} and early 12 lead electrocardiogram. The most powerful predictor of ischaemic end points was the presence of non- $Q$ wave infarction $(p=0.0009)$; a history of previous infarction $(p=0.02)$ and having more than two risk factors $(p=0.03)$ were also independently predictive of further ischaemic events. (b) Features of exercise test alone and together with clinical variables. Of the exercise test variables the development of angina on the exercise test was the most powerful predictor of an ischaemic event in the subsequent year $(p=0.0001)$. Although there are strong associations between the development of angina, ST segment depression, and an inability to complete the test (table 2), an inability to complete the test was also an independent predictor of future ischaemic events $(p=0.03)$.

Analysis of the exercise test variables together with 
(a)

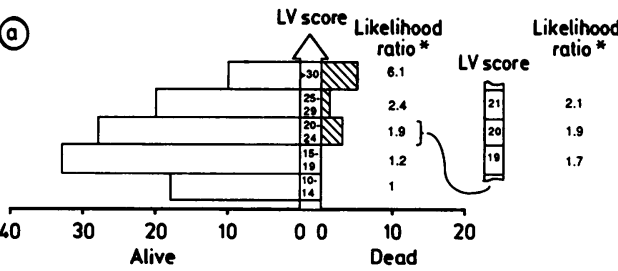

(b)

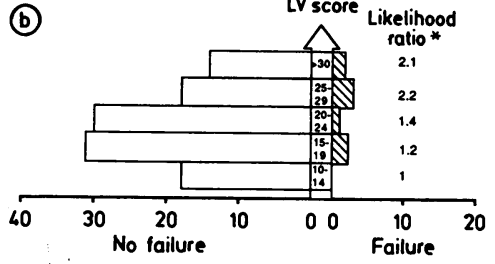

* For cut-off, not for individual LV score group

Fig 3 Left ventricular ( $L V$ ) score as (a) a predictor of mortality and (b) of clinical left ventricular failure.

Likelihood ratios are calculated by comparing the number of end points in patients with all scores above the lower value for each subgroup with those with all scores lower than this value. The score at which the likelihood of an end point is doubled is shown.

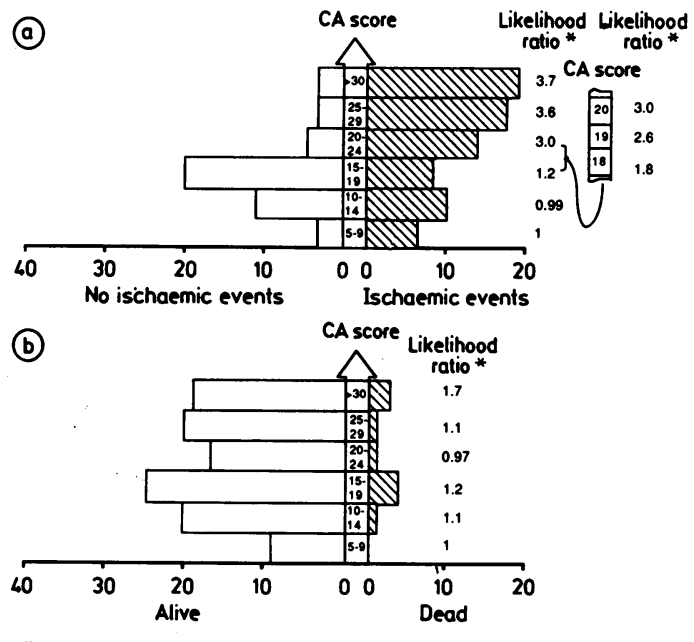

* For cut-off, not for individual LV score group

Fig 4 Coronary artery (CA) score as (a) a predictor of further ischaemic events but (b) not for mortality.

See legend to fig 3 for explanation of likelihood ratios.

the features of the history, electrocardiogram, and early clinical events, showed that angina on the exercise test $(p=0.001)$, the development of angina $>48$ hours after infarction $(p=0.001)$, and the presence of non- $Q$ wave infarction $(p=0.04)$ were independent predictors. Repeat analysis for the separate ischaemic components showed that the development of angina on the exercise test $(p=$
0.0005 ), angina $>48$ hours after infarction ( $p=$ $0.002)$, and non- $Q$ wave infarction $(p=0.008)$ were independent predictors of the development of angina in the first year after discharge. These three variables were also independently predictive of the need for operation $(p=0.003, p=0.008$, and $p=0.001$ respectively). The only predictor of further infarction was the presence of non- $Q$ wave infarction $(p=$ 0.009). (c) All features, including angiographic variables. A high coronary artery score $(\geqslant 19)(p<$ $0.0001)$, the development of angina on the exercise test $(p=0.0008)$, and early angina $(p=0.01)$ were independent predictors of these end points. Analysis for the separate components of this group of end points showed that these variables were independent predictors of angina in the first year after discharge $(p<0.0001, p=0.0001$, and $p=0.03$ respectively); the need for operation was predicted independently by a high coronary score $(p<0.0001)$, non- $Q$ wave infarction $(p=0.001)$, and early angina $(p=0.003)$; non- $Q$ wave infarction was the only predictor for myocardial infarction $(p=0.01)$.

\section{PREDICTORS OF THE DEVELOPMENT OF LEFT VENTRICULAR FAILURE \\ Univariate analysis}

Table 5 shows the variables that predicted this end point together with their associated relative risks. The mean left ventricular score of those who later developed left ventricular failure was higher than that of the patients who did not, but this difference did not reach statistical significance. More detailed analysis showed that patients with a score $\geqslant 25$ or more were twice as likely to develop failure as those with a lower score (fig 3b). The coronary artery score was not predictive for this outcome nor was the collateral score.

\section{Multivariable analysis}

Because a history of previous infarction was the only predictor of this end point, multivariable analysis was not performed on the variables of the history and 12 lead electrocardiogram alone. (a) Features of the exercise test alone and together with clinical variables. From the exercise test an inability to complete the exercise test $(p=0.04)$ and a double product of $\geqslant 10000$ at rest $(p=0.04)$ were both independent predictors for the development of overt left ventricular failure in the year after discharge. For the subgroup of patients who completed the test a heart rate of $\geqslant 140$ beats per minute at six minutes exercise was a powerful predictor of later heart failure $(p=0.0007)$, with other features adding no further prognostic information. The exercise test variables were then analysed with the other features, but as none of the early clinical events was predictive 
of this end point, they were not included in this analysis. The exercise test variables remained independently predictive, but a history of previous infarction did not. (b) All features including angiographic variables. The only independent predictor for left ventricular failure was a double product of $\geqslant 10000$ at the start of the exercise test (p $=0.001)$. For the subgroup of patients who completed six minutes' exercise the only predictor was a heart rate of $\geqslant 140$ beats/min at the end of exercise ( $p$ $=0.01$ ).

\section{Discussion}

Exercise testing is a useful prognostic indicator in patients after myocardial infarction..$^{1-416-19}$ Undue emphasis should not be placed on one investigation, without consideration of its value in relation to other clinical data. Univariate analysis of diagnostic features that predict an outcome does not take into account their interrelations with other variables. Multivariable analysis gives results that are more valuable in clinical practice because this method identifies those clinical features that are the most useful predictors of outcome. In addition, the use of likelihood ratios provides a more meaningful analysis for the clinician than a list of significance values for each variable. ${ }^{14}$

It is important to define the population that has been investigated in a clinical study. We investigated consecutive survivors of myocardial infarction who were clinically stable seven days after admission to hospital. The demographic details of our patient group differ from other studies of men $^{20}$ or nonconsecutive patients. ${ }^{2021}$ We set out to evaluate the contribution of the exercise test in identifying high risk groups among clinically stable survivors of infarction. The exclusion criteria mean that $13 \%$ of the patients did not perform an exercise test. As with other studies, ${ }^{4178}$ the mortality of this exclusion group was higher than that in the exercise test group (19\% in the first year compared with $6 \%$ ). This was expected because the excluded group contained patients with high risk factors and other important medical conditions.

An early submaximal treadmill exercise test was performed by $87 \%$ of all the clinically stable survivors we identified. We had hoped to include all patients fitting the entry criteria for the study protocol, but further analysis of the exclusion group showed that a disproportionate number of women did not perform the exercise test; this may be because the general physicians under whose care they had been admitted tended to treat women more conservatively. The exclusion group was significantly older than those who exercised; this is partly because older patients were more likely to have other midical conditions that prevent them from performing the test.

In some reports the study group contained proportionately more patients with inferior infarction, ${ }^{2} 1820$ because of the exclusion or selection criteria. It becomes difficult under these circumstances to extrapolate to all survivors of infarction. In our study there were equal numbers of patients with anterior and inferior infarcts in the group that performed an exercise test. Exclusion of patients with heart failure $^{2022}$ early after infarction may select out patients with large anterior infarcts and this limits the value of the exercise test in predicting late complications.

The analysis of risk factors in this study emphasises the association between smoking and myocardial infarction..$^{23}$ Analysis of the interrelations between risk factors and other demographic data showed some interesting associations. Women were older and more likely to have a family history of coronary disease and a history of hypertension than men. Multiple risk factors were shown to have an additive effect in the prediction of future ischaemic events. Analysis of the demographic data also showed that Asians and diabetic patients were more likely to be lost to follow up.

Use of a predischarge submaximal exercise test to distinguish high and low risk groups ${ }^{7}$ is a compromise between a maximal exercise test protocol, ${ }^{2} 16^{24-26}$ and a delayed exercise test performed six weeks or more after infarction, which may miss those at highest risk of early clinical events. ${ }^{1627}$ The early submaximal exercise test was found to be safe and to have powerful discriminating power; all clinical end points were more common in those with a positive test than those with a negative test. Those with a positive test were 13 times more likely to die in the first year after infarction. The low mortality of the group with negative exercise tests supports a policy restricting the use of angiography to those with a positive exercise test.

Multivariable analysis showed that ventricular arrhythmias occurring $>\mathbf{7 2}$ hours after infarction but before discharge and during the exercise test were independent predictors of mortality, but when the angiography was added to the analysis the extent of left ventricular damage replaced exercise induced arrhythmias as an independent marker for this end point. Similarly, angina (early) after infarction, angina occurring during the exercise test, and the prescence of non- $Q$ wave infarction were independent predictors of all ischaemic end points in the first year after discharge. When angiographic variables were added to the analysis, however, the extent of coronary disease replaced non- $Q$ wave infarction as an independent predictor. Sub-analysis for the separate ischaemic end points showed that the extent 
of coronary disease and angina occurring early and during exercise predicted the development of angina later in the year. The need for operation was predicted independently by the extent of coronary disease, the development of early angina, and non- $Q$ wave infarction but not independently by the development of angina during the exercise test. Of all these variables, only non- $Q$ wave infarction predicted further infarction. A double product $\geqslant 10000$ before exercise testing was the only independent predictor of future left ventricular failure. When a left ventricular score $\geqslant 21$ was considered this gave no additional prognostic information, but the likelihood of this event was related to the extent of ventricular damage. A score of 21 was selected because it was not only the mean for the group who had angiography but it was also the level at which the odds of dying were doubled by a high score $(\geqslant 21)$.

The criteria used to define a positive exercise test have thus been confirmed as being useful markers for clinical end points. We did not include ST elevation in the infarct zone of the electrocardiogram as a criterion for a positive exercise test. Because some patients with this feature went into the negative group and thus did not undergo cardiac catheterisation, we can draw no conclusions on the relative values of this criterion and the variables generated by angiography. Although in this study it was not itself predictive of first year mortality, there was an association between ST elevation and the development of ventricular arrhythmias on the exercise test and we have data (not yet published) to support other groups' findings that it is associated with the extent of left ventricular damage. ${ }^{2128} 29$ When the discriminatory power of a positive exercise test was reanalysed with ST elevation included as a feature, the test became $100 \%$ sensitive in predicting mortality, although it was less specific.

Conclusions about outcome established by the analysis of this study group reflect the natural history after infarction as modified by current treatment. It was intended that all patients with a positive exercise test should receive a $\beta$ blocker; not all patients could tolerate this treatment, either because of poor left ventricular function or chronic obstructive airways disease. Antianginal treatment (whether medical or surgical), treatment for heart failure, and antiarrhythmic treatment were added as appropriate. Those with negative exercise tests were managed at the discretion of their referring physicians; not all received $a \beta$ blocker and despite a lack of standardised management, the one year mortality in this group was small (one of 113 patients with complete follow up, $0.9 \%, 95 \%$ confidence interval $0.02-4.6 \%$ ).

The early clinical features available to the physician (including features of the chest radiograph and electrocardiogram) have been used in several risk stratification scores..$^{30}$ We studied patients who were haemodynamically stable and who were about to go home after infarction. We attempted to consider not only their overall risk for dying, but also the variables that are able to predict specific end points that might have been avoided by specific treatments. We do not propose that submaximal exercise testing should replace previous stratification scores, but rather than they should supplement them when haemodynamically stable patients are about to be discharged home.

Risk stratification after infarction permits the identification of low risk patients who can be reassured, need few follow up examinations, and may not need secondary preventive medication. Appropriate treatment resources can then be concentrated on the high risk groups. The early development of clinical events (such as cardiogenic shock or continuing ischaemic pain) will identify one high risk group. For those being discharged from hospital, it has been established that the use of $\beta$ blockers improves the chance of survival in the first year after infarction ${ }^{32}$; however, patients with poor left ventricular function may not tolerate these drugs. This study showed that despite their use (and that of other standard treatments such as coronary artery surgery and antiarrhythmic agents), high risk groups are still discernible. Coronary artery bypass grafting improves prognosis for patients with certain arteriographic patterns of disease, ${ }^{33-35}$ and it is probable that this is valid for patients after infarction. ${ }^{36}$ Studies need to be conducted to establish whether the benefits of other specific treatment regimens outweighs their hazards, and those patients most likely to be helped must be identified. A protocol that used submaximal exercise testing followed by left ventricular and coronary angiography in selected patients provides a powerful means of identifying those at risk of future clinical events, as long as the relative predictive powers of the many variables provided are appreciated.

This paper shows that an early submaximal exercise test safely identifies groups at high risk of several outcomes. Patients who are not exercised constitute a high risk group for the reasons discussed. Patients with a negative exercise test have a very low mortality. For patients with a positive test, the use of multivariable analysis shows the relative power of one variable in relation to other clinical and angiographic variables. Not only is prediction better than clinical and electrocardiographic variables aloned, but the selection of patients with a positive test for cardiac catheterisation further refines risk stratification and identifies patients who are more likely to benefit from early operation. Further studies are 
required to investigate the role of specific treatments in those identified to be at highest risk of certain clinical outcomes.

\section{References}

1 Theroux P, Waters DD, Halphen C, DeBaisieux J, Mizgala HF. Prognostic value of exercise testing soon after myocardial infarction. $N$ Engl J Med 1979;301: 341-5.

2 Davidson DM, DeBusk RF. Prognostic value of a single exercise test three weeks after uncomplicated myocardial infarction. Circulation 1980;61:236-42.

3 Weld FM, Chu KL, Bigger JT Jr, Rolnitzky LM. Risk stratification with low-level exercise testing two weeks after acute myocardial infarction. Circulation 1981;64:306-14.

4 Jennings K, Reid DS, Hawkins T, Julian DJ. Role of exercise testing early after myocardial infarction in identifying candidates for coronary surgery. $\mathrm{Br} \mathrm{Med} \mathrm{J}$ 1984;288:185-7.

5 Akhras F, Upward J, Stott R, Jackson G. Early exercise testing and coronary angiography after uncomplicated myocardial infarction. $\mathrm{Br}$ Med J 1982;284: 1293-4.

6 Mannering D, Bennett ED, Ward DE, et al. Accurate detection of triple vessel disease in patients with exercise induced ST segment depression after infarction. Br Heart J 1987;57:133-8.

7 Weiner DA. Role of exercise testing after myocardial infarction. J Am Coll Cardiol 1986;8:1020-1.

8 Taylor GJ, Humphries JO, Mellits ED, et al. Predictors of clinical course, coronary anatomy and left ventricular function after recovery from acute myocardial infarction. Circulation 1980;62:960-70.

9 Sanz G, Castaner A, Bertriu A, et al. Determinants of prognosis in survivors of myocardial infarction: a prospective clinical angiographic study. $N$ Engl J Med 1982;306:1065-70.

10 Moss AJ, Davis HT, DeCamilla J, Bayer LW. Ventricular ectopic beats and their relation to sudden and nonsudden cardiac death after myocardial infarction. Circulation 1979;60:998-1003.

11 Bigger JT Jr, Fleiss JL, Kleiger R, Miller JP, Rolnitzky LM, and the Multicenter Post-Infarction Research Group. The relationships among ventricular arrhythmias, left ventricular dysfunction, and mortality in the two years after myocardial infarction. Circulation 1984;69:250-8.

12 Hammermeister KE, DeRouen TA, Dodge HT. Variables predictive of survival in patients with coronary disease. Selection by univariate and multivariate analyses from the clinical, electrocardiographic, exercise, arteriographic, and quantitative angiographic evaluations. Circulation 1979;59:421-30.

13 Taylor GJ, Humphries JO'N, Mellits ED, et al. Predictors of clinical course, coronary anatomy and left ventricular function after recovery from acute myocardial infarction. Circulation 1980;62:960-70.

14 Sackett DL, Haynes RB, Tugwell P. Clinical epidemiology. $A$ basic science for clinical medicine. Boston/Toronto: Little, Brown, 1985.
15 Principal Investigators of CASS and their Associates. The National Heart, Lung, and Blood Institute Coronary Artery Surgery Study (CASS). Circulation 1981;63(suppl I):1-65.

16 De Feyter PJ, van Eenige MJ, Dighton DH, Visser FC, De Jong J, Roos JP. Prognostic value of exercise testing, coronary angiography and left ventriculography six to eight weeks after myocardial infarction. Circulation 1982;66:527-36.

17 Fioretti P, Brower RW, Simoons ML, et al. Prediction of mortality in hospital survivors of myocardial infarction. Comparison of predischarge exercise testing and radionuclide ventriculography at rest. Br Heart J 1984;52:292-8.

18 Krone RJ, Gillespie JA, Weld FM, Miller JP, Moss AJ, and the Multicenter Postinfarction Research Group. Low-level exercise testing after myocardial infarction: usefulness in enhancing clinical risk stratification. Circulation 1985;71:80-9.

19 Handler CE. Submaximal predischarge exercise testing after myocardial infarction: prognostic value and limitations. Eur Heart J 1985;6:510-7.

20 Sami M, Kraemer H, DeBusk RF. The prognostic significance of serial exercise testing after myocardial infarction. Circulation 1979;60:1238-46.

21 Lahiri A, Balasubramanian V, Millar Craig MW, Crawley J, Raftery EB. Exercise-induced ST segment elevation. Electrocardiographic, angiographic, and scintigraphic evaluation. Br Heart J 1980;43:582-8.

22 Fubini A, Cecchi E, Spinnler MT, et al. Use of radionuclide angiography and an electrocardiographic stress test to diagnose multivessel disease after a first episode of uncomplicated myocardial infarction. Br Heart J 1986;55:535-42.

23 Ball K. Stopping smoking cuts coronary mortality. Health Trends 1987;19:11-3.

24 Cleempoel H, Vainsel H, Bernard R, et al. Predictors of early death after acute myocardial infarction: two months follow-up. Eur Heart J 1986;7:305-11.

25 Jelinek VM, McDonald IG, Ryan WF, Ziffer RW, Clemens A, Gerloff J. Assessment of cardiac risk 10 days after uncomplicated myocardial infarction. $\mathrm{Br}$ Med J 1982;284:227-30.

26 Jespersen CM, Kassis E, Edeling C-J, Madsen JK. The prognostic value of maximal exercise testing soon after first myocardial infarction. Eur Heart J 1985; 6:769-72.

27 Peart I, Seth L, Albers C, Odemuyiwa O, Hall RJC. Post-infarction exercise testing in patients under 55 years. Relation between ischaemic abnormalities and the extent of coronary artery disease. Br Heart J 1986; 55:67-74.

28 Sullivan ID, Davies DW, Sowton E. Submaximal exercise testing early after myocardial infarction. Prognostic importance of exercise induced ST segment elevation. Br Heart J 1984;52:147-53.

29 de Feyter PJ, Majid PA, van Eenige MJ, Wardeh R, Wempe FN, Roos JP. Clinical significance of exercise-induced ST segment elevation. Correlative angiographic study in patients with ischaemic heart disease. Br Heart J 1981;46:84-92.

30 Norris RM, Brandt PWT, Caughey DE, Lee AJ, Scott 
PJ. A new coronary prognostic index. Lancet 1969;i 274-8.

31 Killip T III, Kimball JT. Treatment of myocardial infarction in a coronary care unit. A two year experience with 250 patients. Am J Cardiol 1967;20: $457-64$

32 Yusuf S, Peto R, Lewis J, Collins R, Sleight P. Beta blockade during and after myocardial infarction: an overview of the randomized trials. Prog Cardiovasc Dis 1985;XXVII:335-71.

33 European Coronary Surgery Study Group. Prospective randomized study of coronary bypass surgery in stable angina pectoris. Lancet 1980;i1:491-5.
34 DeRouen TA, Hammermeister KE, Dodge HT. Comparison of the effects on survival after coronary artery surgery in subgroups from the Seattle Heart Watch. Circulation 1981;63:537-45.

35 CASS Principal Investigators and their Associates. Coronary artery surgery study (CASS): a randomized trial of coronary artery bypass surgery. Survival data. Circulation 1983;68:939-50.

36 Akhras F, Upward J, Keates J, Jackson G. Early exercise testing and elective coronary artery bypass surgery after uncomplicated myocardial infarction. Effect on morbidity and mortality. Br Heart $J$ 1984; 52:413-7. 